\title{
Effect of Four Bleaching Regimens on Color Changes and Microhardness of Dental Nanofilled Composite
}

\author{
Simone Xavier Silva Costa, ${ }^{1}$ Anne Buss Becker, ${ }^{2}$ Alessandra Nara de Souza Rastelli, ${ }^{1,3}$ \\ Leonor de Castro Monteiro Loffredo, ${ }^{1}$ Marcelo Ferrarezi de Andrade, ${ }^{1}$ \\ and Vanderlei Salvador Bagnato ${ }^{3}$ \\ ${ }^{1}$ Department of Restorative Dentistry, Araraquara School of Dentistry, University of São Paulo State, \\ 1680 Humaitá Street 14801-903, Araraquara, SP, Brazil \\ ${ }^{2}$ University Center Franciscano (UNIFRA), 1250 Andradas Street 97010-030, Santa Maria, RS, Brazil \\ ${ }^{3}$ Physics Institute of São Carlos, University of São Paulo, 400 Trabalhador São Carlense Avenue 13560-970, São Carlos, SP, Brazil
}

Correspondence should be addressed to Alessandra Nara de Souza Rastelli, alerastelli@yahoo.com.br

Received 19 March 2009; Accepted 19 August 2009

Recommended by Toru Nikaido

Objective. The purpose of this study was to compare the color changes and microhardness of a nanocomposite after four bleaching regimens. Materials. Twenty-five specimens $(n=25)$ were made with a nanocomposite resin (Filtek Supreme XT). The specimens were divided into five groups equally $(n=5)$ : bleaching groups and control group, as follows: G1: artificial saliva at $37^{\circ} \mathrm{C}$; (control) G2: hydrogen peroxide (HP) at 7\%; G3: hydrogen peroxide (HP) at 35\%; G4: carbamide peroxide (CP) at 10\%; G5: carbamide peroxide (CP) 35\%. Color measurements were made with spectrophotometer using CIELAB color scale. The Vickers hardness $(\mathrm{VHN})$ measurements were performed at the top surface. The data were analyzed with two-way Analysis of Variance. Results. $\Delta \mathrm{E}$ and VHN mean values into the groups were not statistically different, however, the VHN mean values before and after storage and bleaching showed statistically significant differences. Conclusion. Nanocomposite samples showed no significant alteration (color and microhardness) after bleaching. Thus, no replacement of restorations is required after bleaching.

Copyright ( 2009 Simone Xavier Silva Costa et al. This is an open access article distributed under the Creative Commons Attribution License, which permits unrestricted use, distribution, and reproduction in any medium, provided the original work is properly cited.

\section{Introduction}

The use of bleaching agents to improve the appearance of natural dentition has become a popular procedure since their introduction by Haywood and Heymann [1]. Currently, the bleaching agents are based primarily on hydrogen peroxide (HP) or its compounds such as carbamide peroxide (CP). The bleaching agents provide whitening of tooth structure through decomposition of peroxides into unstable free radicals. These radicals further breakdown into large pigmented molecules either through an oxidation or a reduction reaction. The oxidation/reduction process changes the chemical structure of interacting organic substances of tooth, which results in color change $[2,3]$. However, the application of bleaching agents can affect human teeth and restorative materials.
Effect of bleaching on dental restorative materials in general has been reviewed recently [4]. Due to their organic matrix, composite resin materials especially are more prone to chemical alteration compared to inert metal or ceramic restorations [5]. Although the application of low concentrations of $\mathrm{CP}$ on tooth structure causes minimal surface changes $[6,7]$, however high-concentration solutions modify the enamel surface [8]. Bleaching agents also deteriorate the surface of existing composite restorations and induce bacterial adhesion [9].

The use of bleaching agents is widespread, however studies investigating the effect of bleaching treatments on the microhardness of restorative materials have reported conflicting results [10-14].

The effects of $\mathrm{CP}$ (home bleaching) on the surface microhardness are material-dependent [13, 15-17]. Significant 
increase in the surface microhardness of glass-ionomer cement after exposure to $15 \% \mathrm{CP}$ was verified $[17,18]$. However, bleaching agents produced a significant microhardness decrease for compomer [11, 12]. No significant surface microhardness changes were found after application of $15 \%$ CP for composite resin [17]. However, other studies show that the bleaching agents do not reduce the microhardness of the restorative materials $[19,20]$.

Bleaching agents may affect the color of existing composite restorations. The color change of polyacid-modified composites is generally higher than the change recorded for hybrid and macrofilled composites. Thus, the effect of bleaching agents on the color of restorative materials are material-dependent [21].

Several studies show the effects of peroxide-based bleaching agents on dental restorative materials. Generally, these studies indicate that the effects of bleaching agents are minor and clinically insignificant as slight roughening of composite resin surfaces. The bleaching agents do not perceptibly change the shade of tooth-colored restorative materials [22].

Recently, a nanofilled resin composite with primary filler size of 5-20 nm was introduced [23]. A composite dental filling material that could be used in all areas of the mouth with high initial polish and superior polish retention (typical of microfills), as well as excellent mechanical properties suitable for high stress-bearing restorations (typical of hybrid composites) [24]. Because of these properties the nanofilled composite may present smaller changes of bleaching agents. Its surface properties may be different from those of hybrid composites.

Although there are several reports on the effect of home bleaching systems on composites [25, 26], little is known about the effects of the in-office bleaching technique on the restorative materials $[4,11]$. There is limited data in literature on the effects of bleaching systems on microhybrid and nanofilled composite resins. Thus, the purpose of this study was to evaluate the effects of four bleaching regimens on color changes and microhardness of nanofilled composite resins.

\section{Material and Methods}

The light-cured composite material used in the study was Filtek Supreme XT (batch number 6BN ET-2181/01, 3M ESPE, Dental Products St. Paul, Minn, USA) (Table 1).

For the color and microhardness measurements specimens with $8 \mathrm{~mm}$ in diameter and $1 \mathrm{~mm}$ thickness were made in a metallic mold. The composite resin was packed into the mold, with the upper and lower surfaces covered with acetate matrix strips. The specimens were light-cured during 40 seconds by a light-curing unit- (LCU) based on LED (LEC 1000, MM Optics, São Carlos, SP, Brazil). The LCU was calibrated before light-curing process of the composite resin, and the power density of $500 \mathrm{~mW} / \mathrm{cm}^{2}$ was obtained by the use of a power meter (Fieldmaster, Coherent-model $n^{\circ} \mathrm{FM}$, set $n^{\circ}$ WX65, part n० 33-0506, USA).

Following light-curing, the specimens were removed from the molds and placed at $37^{\circ} \mathrm{C}$ distilled water for 24 hours to assure complete polymerization.
2.1. Color Measurements. Initial quantitative color $(\Delta \mathrm{E})$ measurements were performed by the use of a spectrophotometer (Pocket Spee-ColorQA Pro, PocketSpee Techonologies Inc., Denver, Colo, USA). During baseline measurements, three measurements were performed for each specimen, and the mean of the readings was calculated. The mean of each specimen was calculated by use of the CIE Lab uniform color scale.

The magnitude of the total color difference is represented by a single number $\Delta \mathrm{E}^{(\mathrm{CIE}, 1971)}: \Delta \mathrm{E}=\left[\left(\Delta L^{*}\right)^{2}+\right.$ $\left.\left(\Delta a^{*}\right)^{2}+\left(\Delta b^{*}\right)^{2}\right]^{1 / 2}$, where $L^{*}$ represents lightness, $a^{*}$ redness-greenness and $b^{*}$ yellowness-blueness. This formula provides numeric data that represent the differences in color perceived between 2 objects.

The specimens were then randomly divided into 5 groups $(n=5)$ :

(i) Group 1: stored in artificial saliva at $37^{\circ} \mathrm{C}$ for three weeks and served as control;

(ii) Group 2: specimens were treated with hydrogen peroxide at 7\% for four hours per day for two weeks;

(iii) Group 3: specimens were treated with hydrogen peroxide at $35 \%$ (three sessions of $30 \mathrm{~min}$ each at intervals of one week);

(iv) Group 4: specimens were treated with carbamide peroxide at $10 \%$ for four hours per day for two weeks;

(v) Group 5: specimens were treated with carbamide peroxide at 35\% (three sessions of 30 minutes each at intervals of one week).

During the test period, the specimens were kept at $37^{\circ} \mathrm{C}$ and $100 \%$ relative humidity. Each day after the active treatment period the specimens were rinsed with distilled water to remove the bleaching agents and stored in artificial saliva. At the end of the bleaching regimens, color changes measurements of the control and the test groups were obtained as previously described. All specimens were measured three times and the average values were calculated.

2.2. Microhardness Measurements. After curing and storage for 24 hours the top surfaces of all specimens were then polished with a sequential series of 3 (medium, fine, and superfine) Sof-Lex disks (3M ESPE) and a slow-speed handpiece. The specimens were then randomly divided into 5 groups $(n=5)$ as already reported for the color's assessment.

The specimens were blotted dry and positioned beneath the indenter of a microhardness tester Micromet 2100 (Buehler, Lake Bluff, Ill, USA). A $50 \mathrm{~g}$ load was applied through the indenter, with a dwell time of 30 seconds. This method depended on visualization of the surface indentations through the microscope of the testing machine. The length of the diagonal of each indentation was measured directly from the graduated eyepiece of the microscope in the testing machine. Four indentations were made at random on the top surface of each specimen, and a mean value was calculated as the microhardness for that specimen. Microhardness was measured at 24 hours after polymerization (baseline), at the end of the bleaching regimens (three weeks) on the same specimen. 
TABLE 1: Characteristics of restorative material used in the study (manufacturers' informations).

\begin{tabular}{|c|c|c|c|c|c|c|}
\hline Material & Manufacturer & Shade & Material type & Matrix & Filler size & Filler Volume \\
\hline $\begin{array}{l}\text { Filtek } \\
\text { Supreme XT }\end{array}$ & 3M ESPE & $\mathrm{A}_{3} \mathrm{E}$ & $\begin{array}{l}\text { Nanofilled } \\
\text { composite }\end{array}$ & $\begin{array}{l}\text { Bis-GMA, } \\
\text { Bis-EMA, } \\
\text { UDMA, } \\
\text { TEGDMA. }\end{array}$ & $\begin{array}{l}\text { Agglomerated/non-aggregated of } \\
75 \mathrm{~nm} \text { silica nanofiller and a } \\
\text { loosely bound agglomerate silica } \\
\text { nanocluster consisting of } \\
\text { agglomeratesof primary silica } \\
\text { nanoparticles of } 75 \mathrm{~nm} \text { size } \\
\text { fillers. The cluster size range is } \\
0.6-1.4 \text { microns. }\end{array}$ & $72.5 \%$ \\
\hline
\end{tabular}

TABLE 2: Mean and standard deviation ( \pm sd) $\Delta \mathrm{E}$ values for all experimental groups.

\begin{tabular}{lcc}
\hline Experimental groups & Mean & Standard deviation $( \pm \mathrm{sd})$ \\
\hline 1 (Control) & 28.64 & 1.10 \\
2 (Hydrogen peroxide 7\%) & 30.18 & 2.05 \\
3 (Hydrogen peroxide 35\%) & 29.27 & 0.97 \\
4 (Carbamide peroxide 10\%) & 29.65 & 1.33 \\
5 (Carbamide peroxide 35\%) & 29.13 & 1.21 \\
\hline
\end{tabular}

2.3. Statistical Analysis. The data were analyzed by Analysis of Variance (ANOVA) with Stata Software (Stata Statistical Software: Release 8.0, College Station, Stata Corporation, Tex, USA) at level significance of $5 \%$.

\section{Results}

3.1. Color Measurements. Table 2 shows the mean $\Delta \mathrm{E}$ values for the different groups. The results showed that the differences were not statistically significant among groups $(P=.4989)$. The $\Delta \mathrm{E}$ values of each bleaching regimens were analyzed by Analysis of Variance and the data showed that all four bleaching regimens had no significant effect on the color of nanofilled composite resin Filtek Supreme XT (3M ESPE, Dental Products St. Paul, Minn, USA).

Comparing the mean color changes performed in each one of the five groups, it can be seen that they were homogeneous and this finding can point out to the same results in the use of these four bleaching regimens (Figure 1).

3.2. Microhardness Measurements. Means and standard deviations of the $\mathrm{VH}$ of the specimens at baseline and after bleaching regimens are shown in Tables 3 and 4 . The difference between the $\mathrm{VH}$ values (baseline and after bleaching) were statistically significant $(P<.01)$. The $\mathrm{VH}$ values after storage and bleaching was significantly lower in comparison to baseline values.

All solutions, either storage (artificial saliva) or treatment (bleaching agents) affected VHN of the restorative material at all the levels evaluated. However, storage in artificial saliva and bleaching regimens promoted significant decrease in VHN mean values for all Groups tested.

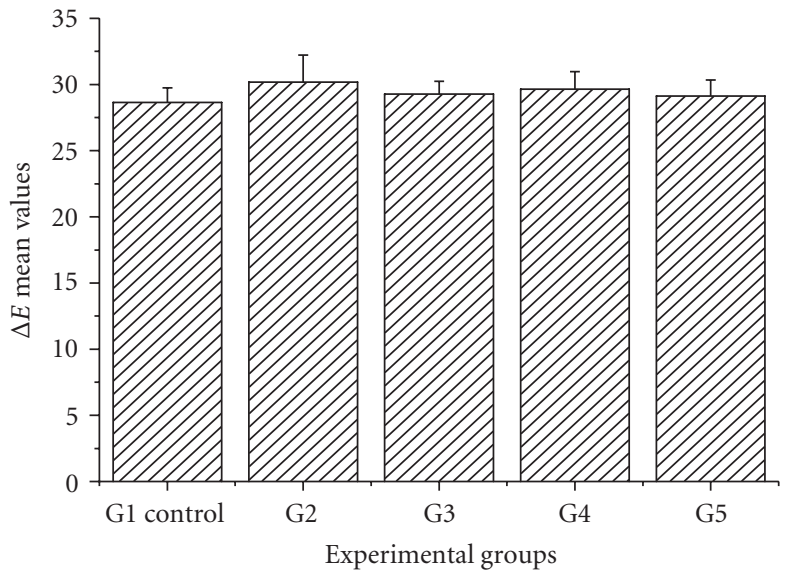

Figure 1: Mean $\Delta \mathrm{E}$ values for all Groups (G1: control; G2: Hydrogen peroxide 7\%; G3: Hydrogen peroxide 35\%; G4: Carbamide peroxide 10\%; G5: Carbamide peroxide 35\%).

TABle 3: Mean values and standard deviation ( \pm sd) for VHN (baseline).

\begin{tabular}{lc}
\hline Bleaching regimens & Mean values $( \pm$ sd $)$ \\
\hline G1 & $75.6( \pm 6.0)$ \\
G2 & $76.6( \pm 4.6)$ \\
G3 & $75.2( \pm 5.3)$ \\
G4 & $74.0( \pm 8.4)$ \\
G5 & $72.7( \pm 6.7)$ \\
\hline
\end{tabular}

TABLe 4: Mean values and standard deviation $( \pm$ sd) for VHN (after bleaching).

\begin{tabular}{lc}
\hline Bleaching regimens & Mean values $( \pm$ sd $)$ \\
\hline G1 & $34.9( \pm 1.6)$ \\
G2 & $37.4( \pm 2.6)$ \\
G3 & $36.1( \pm 3.3)$ \\
G4 & $37.1( \pm 1.4)$ \\
G5 & $36.1( \pm 2.5)$ \\
\hline
\end{tabular}

Similar VHN values was observed in bleached samples, that is, from specimens treated with HP (7\% and 35\%) and CP $(10 \%$ and $35 \%)$, as well as samples of the positive control. Thus, after bleaching regimens, no significant differences were found among Groups. The Figure 2 shows the results of microhardness for baseline and after bleaching procedures. 


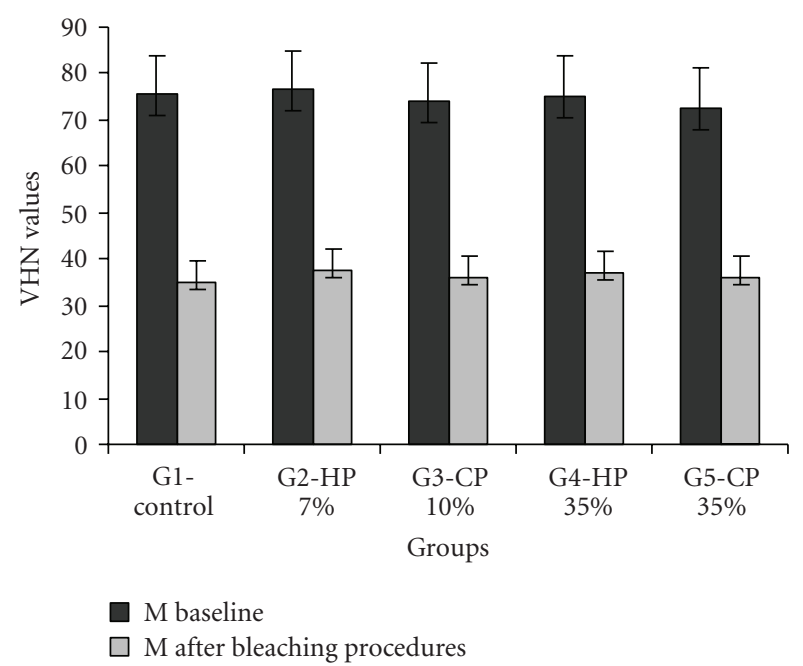

FIGURE 2: Microhardness mean values (M) and standard deviation (SD) for all Groups baseline and after bleaching procedures (G1: control; G2: Hydrogen peroxide 7\%; G3: Hydrogen peroxide 35\%; G4: Carbamide peroxide 10\%; G5: Carbamide peroxide 35\%).

\section{Discussion}

Today "whiter teeth" is the most common aesthetic request from dental patients and tooth whitening is a relatively noninvasive approach to achieving this goal. As bleaching of teeth has become extremely popular, the effect of bleaching on aesthetic appearance of dental materials must be considered. This complicates the process of trying to establish and maintain good color match between the dental restoration and the adjacent tooth structure. Changes in the chemical and morphological structure of restorations must be of concern when bleaching is used as a whitening treatment $[8,26,27]$.

The contemporary tooth bleaching technique is based primarily on the oxidation by hydrogen peroxide or one of its precursors, and those are often used in combination with an activating agent such as heat or light. The commercial products of tooth bleaching are usually fabricated in a gel form and can be administered professionally in dental clinics (in-office bleaching) or used by patients with trays at home (home bleaching). Current available agents are usually based on 6-20 and 25\%-40\% peroxide gels for home and in-office whitening, respectively $[8,27]$.

Patients seeking bleaching treatment may have teeth restored with different kinds of aesthetic restorative material. It is possible that chemical softening, resulting from bleaching, may affect the clinical durability of these materials. Drastic color changes to existing restorations may compromise esthetics; therefore it is important to understand the effect of bleaching agents on the color of restorative materials. The interaction between the bleaching agent and restorative material is of clinical significance because the color change may be noticed by the patient $[17,21]$.

After the application of bleaching agents, whitening of tooth results from oxidation of organic substances by free radicals [3]. In case of dental composite resins, bleaching agents may have an influence on resin matrix, filler, or both. However, fillers are basically glass or ceramic, and therefore the influence of hydrogen peroxide on fillers would be very small. Instead, the resin matrix may be chemically degraded by the concentrated or repeated application of hydrogen peroxide [28].

Several studies have evaluated the effects of bleaching on dental hard tissues [7, 29-32]. A recently published review showed that tooth-bleaching agents may have negative effects on dental restorative materials. The effects included changes on surface morphology and also in their chemical and physical properties [4]. Yalcin and Gurgan [26], showed that the gloss of tooth colored restorative materials were significantly decreased by the bleaching regimens. Thus, bleaching agents should not be used indiscriminately when these restorations are present.

Nevertheless, because literature presents controversial findings, the influence on physical properties and surface morphology of dental materials needs a closer approach. Some authors have reported microstructural changes and decreased hardness in restorative materials after bleaching $[13,25]$, while other studies found only slight changes or no changes $[13,33,34]$. Furthermore, the interaction between office solutions and both, teeth and restorations still raises concern, once higher peroxide concentrations could worsen possible harmful effects [35].

This statement is in accordance with Monaghan et al. $[36,37]$ where highly concentrated office bleaching systems affected the color of composite resin, however low concentrations of home bleaching systems did not.

Cooley and Burger [38] evaluated composite resins for changes in surface hardness, roughness, and lightness after exposure to $10 \%$ carbamide peroxide gels and found that these three parameters increased significantly after exposure. Cullen et al. [39] reported that 10\% carbamide peroxide and $30 \%$ hydrogen peroxide had no significant effect on tensile strength of highly filled composite resins. However, microfilled composite resins were significantly affected by $30 \%$ hydrogen peroxide, resulting in a reduction in tensile strength. Canay and Cehreli [21] showed that 10\% hydrogen peroxide provided more color changes of composite resins compared with $10 \%$ carbamide peroxide, and the color change of all composite resins bleached with hydrogen peroxide solution was clinically detectable to the naked eye. Lima et al. [40] showed that $16 \%$ carbamide peroxide reduced the microhardness of the hybrid composite surface, independent of the type of light source used.

The bleaching regimens used in this study did not have any significant effect on the color changes and microhardness for the material tested. These findings coincide with the results of $\mathrm{Kim}$ et al. [28] where the influence of toothwhitening film and strip on the color and surface roughness of dental composite resins was negligible. Also, there was no difference in the color change and surface roughness according to the type of composite resin, whether nanofilled or microhybrid. In other study [17], the 15\% carbamide peroxide did not cause any significant effect on the surface microhardness for all composite resins tested (Filtek Z350 and Filtek P-60/3M ESPE) and the effects of 15\% 
carbamide peroxide on the surface microhardness were material-dependent.

The nanofilled composite was development for used in all areas of the mouth with high initial polish and superior polish retention (typical of microfills), as well as excellent mechanical properties suitable for high stressbearing restorations (typical of hybrid composites). This recent tooth-colored restorative material was used in this study. Changes in the structure or composition of this restorative material may have provided more resistant surfaces against bleaching treatments [19]. The composite resin Filtek Supreme XT (3M ESPE) as a nanofilled composite has an average particle size $0.6-1.4$ microns. This may be another reason why Filtek Supreme XT (3M ESPE) with smaller filler size has the highest polishing and consequently, smaller effect from bleaching agents.

The results after bleaching regimens showed that bleaching did not affect the color and microhardness of composite resin, even after 4 hours of application of hydrogen peroxide $7 \%$ and carbamide peroxide $10 \%$ over a period of 14 days (home bleaching) and even after 30 minutes application of hydrogen peroxide and carbamide peroxide $35 \%$ over a period for three sessions (office bleaching). These results are consistent with previous studies for the low concentration of carbamide peroxide bleaching products $[21,28]$, however, not for the high concentrated bleaching agent.

There is controversy about the impact of low concentrated $10 \%-16 \%$ carbamide peroxide gels on surface microhardness of restorative composite materials. In some investigations softening of composite resins was associated with the application of home-bleaching gels $[25,41]$. Other investigations revealed no significant hardness changes [10, 42] due to application of home-bleaching gels or even an increase in surface hardness $[13,43]$. In-office tooth whiteners (35\% carbamide peroxide or 35\% hydrogen peroxide) did not significantly affect hardness and tensile strength of composite materials [44, 45].

Such wide variations in data suggest that some tooth colored restorative materials may be more susceptible to alteration and some bleaching agents are more likely to cause those alterations [46]. The discrepancies between these studies may be explained by the differences inexperimental methodologies, bleaching agents applied [47], and restorative materials used [13]. The frequency with which the bleaching agents were changed may also contribute to the disparity between the results of the studies. In the present study, bleaching products were applied with clinically relevant bleaching regimes according to manufacturer's instructions. Application periods selected were 4 hours per day for the home-bleaching and 30 minutes for session for the office-bleaching. This was different from several other bleaching studies in which materials were continuously exposed to bleaching products for several days to simulate cumulative effects over time $[11,12]$.

In vitro studies are limited in their attempt to simulate clinical conditions. It was shown that peroxide levels in bleaching products are depleted during use depending on the in vivo situation [47]. In this study, the bleaching agents were not diluted or buffered with any water content such as saliva or distilled water during bleaching treatments, as in most other studies [13, 44-46]. Only after regimens bleaching the specimens were stored in artificial saliva. Storage of composite specimens in saliva between incubation with the bleaching material was done to simulate the clinical situation. It is conceivable that storage in saliva might have modified or attenuated the whitening agent impact by the formation of a surface-protection salivary layer on the restorative material [48].

The bleaching mechanism for teeth is that the active agents (peroxide solutions) can flow freely through the enamel and dentin and oxidize the pigments in the teeth [49]. The results of the present study showed that the color change of composite resin after bleaching was probably due to superficial cleansing of the specimens, not intrinsic color change.

Although bleaching agents can successfully remove the exterior staining from composite resins, they will not bleach them, whereas they can effectively bleach teeth $[6,50]$. Therefore, after bleaching, the composite resin restoration may not match the surrounding bleached tooth structure. Also, bleaching can increase the surface roughness of composite resins; therefore, the restoration may stain more easily after bleaching $[13,16]$. Bleaching agents should be used cautiously to remove the exterior stain on the surface of composite resin restorations.

Colorimetry is a branch of the science of color based on the digital expression of the color perceived from the object. In assessing chromatic differences, generally 2 color systems are used: Munsell Color System and Standard Comission Internationale de L'Eclairage (CIE Lab) Color System. The American Dental Association recommends the use of CIE Lab color differential system [51]. According to this system, all colors in nature are obtained through blending of 3 basic colors, red, blue and green, in various proportions [21].

For standardized and reproducible evaluation of color changes of restorative materials, colorimeters are used analyzing $L^{*} a^{*} b^{*}$ values according to the CIELab-system $[52,53]$. It has been claimed that under clinical conditions in the mouth, DE color differences have been reported to be relevant and perceptible only when higher than 3.3 [54] or 3.6 [55]. In this study the CIELab system was used.

Within the results of the present study, it can be summarized that replacement of the tested restorative materials is not required after in-office bleaching. Polydorou [20] said that there is no sufficient reason to indicate the replacement of restorations, except the cases that have esthetic involvement. Thus, patients should be advised that existing composite restorations may not match the natural teeth after bleaching, and replacement may be required.

\section{Conclusions}

The results obtained for this study indicate that color change and microhardness in the nanofilled composite after bleaching (home-bleaching and office-bleaching) was not perceptible or significant. Therefore, no replacement of restorations is required after bleaching. 


\section{Acknowledgments}

The authors thank 3M ESPE, Brazil, for providing the nanofilled composite resin used in this study and the Physics Institute of São Carlos, University of São Paulo, Brazil, by the use of spectrophotometer from the Biophotonics Laboratory. This study was supported by CAPES/Brazil and São Paulo State University (UNESP), Araraquara School of Dentistry, Brazil.

\section{References}

[1] V. B. Haywood and H. O. Heymann, "Nightguard vital bleaching," Quintessence International, vol. 20, no. 3, pp. 173176, 1989.

[2] D. K. Yarborough, "The safety and efficacy of tooth bleaching: a review of the literature 1988-1990," Compendium of Continuing Education in Dentistry, vol. 12, no. 3, pp. 191-196, 1991.

[3] J. E. Dahl and U. Pallesen, "Tooth bleaching-a critical review of the biological aspects," Critical Reviews in Oral Biology and Medicine, vol. 14, no. 4, pp. 292-304, 2003.

[4] T. Attin, C. Hannig, A. Wiegand, and R. Attin, "Effect of bleaching on restorative materials and restorations-a systematic review," Dental Materials, vol. 20, no. 9, pp. 852861, 2004.

[5] C. Hannig, S. Duong, K. Becker, E. Brunner, E. Kahler, and T. Attin, "Effect of bleaching on subsurface micro-hardness of composite and a polyacid modified composite," Dental Materials, vol. 23, no. 2, pp. 198-203, 2007.

[6] V. B. Haywood, T. Leech, H. O. Heymann, D. Crumpler, and K. Bruggers, "Nightguard vital bleaching: effects on enamel surface texture and diffusion," Quintessence International, vol. 21, no. 10, pp. 801-804, 1990.

[7] C.-P. Ernst, B. B. Marroquin, and B. Willershausen-Zonnchen, "Effects of hydrogen peroxide-containing bleaching agents on the morphology of human enamel," Quintessence International, vol. 27, no. 7, pp. 53-56, 1996.

[8] U. Oltu and S. Gürgan, "Effects of three concentrations of carbamide peroxide on the structure of enamel," Journal of Oral Rehabilitation, vol. 27, no. 4, pp. 332-340, 2000.

[9] C. Mor, D. Steinberg, H. Dogan, and I. Rotstein, "Bacterial adherence to bleached surfaces of composite resin in vitro," Oral Surgery, Oral Medicine, Oral Pathology, Oral Radiology, and Endodontics, vol. 86, no. 5, pp. 582-586, 1998.

[10] F. Garcia-Godoy, A. Garcia-Godoy, and F. Garcia-Godoy, "Effect of bleaching gels on the surface roughness, hardness, and micromorphology of composites," General Dentistry, vol. 50, no. 3, pp. 247-250, 2002.

[11] C.-B. Jung, H.-I. Kim, K.-H. Kim, and Y. H. Kwon, "Influence of $30 \%$ hydrogen peroxide bleaching on compomers in their surface modifications and thermal expansion," Dental Materials Journal, vol. 21, no. 4, pp. 396-403, 2002.

[12] J. H. Lee, H. I. Kim, K. H. Kim, and Y. H. Kwon, "Effect of bleaching agents on the fluoride release and microhardness of dental materials," Journal of Biomedical Materials Research, vol. 63, no. 5, pp. 535-541, 2002.

[13] S. B. Turker and T. Biskin, "Effect of three bleaching agents on the surface properties of three different esthetic restorative materials," Journal of Prosthetic Dentistry, vol. 89, no. 5, pp. 466-473, 2003.
[14] F. Bayindir, K. M. Colak, and I. H. Uzun, "Effect of tooth whitener on microhardness of tooth colour restorative materials," Materials Research Innovations, vol. 13, no. 1, pp. 28-31, 2009.

[15] A. U. J. Yap and P. Wattanapayungkul, "Effects of in-office tooth whiteners on hardness of tooth-colored restoratives," Operative Dentistry, vol. 27, no. 2, pp. 137-141, 2002.

[16] Z. C. Cehreli, R. Yazici, and F. Garcia-Godoy, "Effect of homeuse bleaching gels on fluoride releasing restorative materials," Operative Dentistry, vol. 28, no. 5, pp. 605-609, 2003.

[17] H. Yu, Q. Li, M. Hussain, and Y. Wang, "Effects of bleaching gels on the surface microhardness of tooth-colored restorative materials in situ," Journal of Dentistry, vol. 36, no. 4, pp. 261267, 2008.

[18] I. Campos, A. L. F. Briso, L. A. F. Pimenta, and G. Ambrosano, "Effects of bleaching with carbamide peroxide gels on microhardness of restoration materials," Journal of Esthetic and Restorative Dentistry, vol. 15, no. 3, pp. 175-182, 2003.

[19] A. Mujdeci and O. Gokay, "Effect of bleaching agents on the microhardness of tooth-colored restorative materials," Journal of Prosthetic Dentistry, vol. 95, no. 4, pp. 286-289, 2006.

[20] O. Polydorou, J. S. Mönting, E. Hellwig, and T. M. Auschill, "Effect of in-office tooth bleaching on the microhardness of six dental esthetic restorative materials," Dental Materials, vol. 23, no. 2, pp. 153-158, 2007.

[21] S. Canay and M. C. Cehreli, "The effect of current bleaching agents on the color of light-polymerized composites in vitro," Journal of Prosthetic Dentistry, vol. 89, no. 5, pp. 474-478, 2003.

[22] E. J. Swift Jr., "Effects of bleaching on tooth structure and restorations, part IV: effects on restorative materials," Journal of Esthetic and Restorative Dentistry, vol. 20, no. 3, pp. 206-211, 2008.

[23] D. Ure and J. Harris, "Nanotechnology in dentistry: reduction to practice," Dental update, vol. 30, no. 1, pp. 10-15, 2003.

[24] S. B. Mitra, D. Wu, and B. N. Holmes, "An application of nanotechnology in advanced dental materials," The Journal of the American Dental Association, vol. 134, no. 10, pp. 13821390, 2003.

[25] S. J. Bailey and E. J. Swift Jr., "Effects of home bleaching products on composite resins," Quintessence International, vol. 23, no. 7, pp. 489-494, 1992.

[26] F. Yalcin and S. Gürgan, "Effect of two different bleaching regimens on the gloss of tooth colored restorative materials," Dental Materials, vol. 21, no. 5, pp. 464-468, 2005.

[27] D. J. White, K. M. Kozak, J. R. Zoladz, et al., "Peroxide interactions with hard tissues: effects on surface hardness and surface/subsurface ultrastructural properties," Compendium of Continuing Education in Dentistry, vol. 23, no. 1A, pp. 42-48, 2002.

[28] J. H. Kim, Y. K. Lee, B. S. Lim, S. H. Rhee, and H. C. Yang, "Effect of tooth-whitening strips and films on changes in color and surface roughness of resin composites," Clinical oral investigations, vol. 8, no. 3, pp. 118-122, 2004.

[29] N. C. Bitter, "A scanning electron microscope study of the long-term effect of bleaching agents on the enamel surface in vivo," General Dentistry, vol. 46, no. 1, pp. 84-88, 1998.

[30] V. Cavalli, C. A. G. Arrais, M. Giannini, and G. M. B. Ambrosano, "High-concentrated carbamide peroxide bleaching agents effects on enamel surface," Journal of Oral Rehabilitation, vol. 31, no. 2, pp. 155-159, 2004. 
[31] C.-P. Ernst, B. B. Marroquin, and B. Willershausen-Zonnchen, "Effects of hydrogen peroxide-containing bleaching agents on the morphology of human enamel," Quintessence International, vol. 27, no. 1, pp. 53-56, 1996.

[32] D. F. Murchison, D. G. Charlton, and B. K. Moore, "Carbamide peroxide bleaching: effects on enamel surface hardness and bonding," Operative Dentistry, vol. 17, no. 5, pp. 181-185, 1992.

[33] E. J. Swift Jr., "Restorative considerations with vital tooth bleaching," The Journal of the American Dental Association, vol. 128, no. 4, pp. S60-S64, 1997.

[34] P. Wattanapayungkul, A. U. J. Yap, K. W. Chooi, M. F. L. A. Lee, R. S. Selamat, and R. D. Zhou, "The effect of home bleaching agents on the surface roughness of tooth-colored restoratives with time," Operative Dentistry, vol. 29, no. 4, pp. 398-403, 2004.

[35] R. E. Langsten, W. J. Dunn, G. R. Hartup, and D. F. Murchison, "Higher-concentration carbamide peroxide effects on surface roughness of composites," Journal of Esthetic and Restorative Dentistry, vol. 14, no. 2, pp. 92-96, 2002.

[36] P. Monaghan, T. Trowbridge, and E. Lautenschlager, "Composite resin color change after vital tooth bleaching," The Journal of Prosthetic Dentistry, vol. 67, no. 6, pp. 778-781, 1992.

[37] P. Monaghan, E. Lim, and E. Lautenschlager, "Effects of home bleaching preparations on composite resin color," The Journal of Prosthetic Dentistry, vol. 68, no. 4, pp. 575-578, 1992.

[38] R. L. Cooley and K. M. Burger, "Effect of carbamide peroxide on composite resins," Quintessence International, vol. 22, pp. 817-821, 1991.

[39] D. R. Cullen, J. A. Nelson, and J. L. Sandrik, "Peroxide bleaches: effect on tensile strength of composite resins," The Journal of Prosthetic Dentistry, vol. 69, no. 3, pp. 247-249, 1993.

[40] D. A. N. L. Lima, R. S. De Alexandre, A. C. M. Martins, F. H. B. Aguiar, G. M. B. Ambrosano, and J. R. Lovadino, "Effect of curing lights and bleaching agents on physical properties of a hybrid composite resin," Journal of Esthetic and Restorative Dentistry, vol. 20, no. 4, pp. 266-273, 2008.

[41] S. B. Türker and T. Biskin, "The effect of bleaching agents on the microhardness of dental aesthetic restorative materials," Journal of Oral Rehabilitation, vol. 29, no. 7, pp. 657-661, 2002.

[42] S. A. Nathoo, M. B. Chmielewski, and R. E. Kirkup, "Effects of colgate platinum professional toothwhitening system on microhardness of enamel, dentin, and composite resins," Compendium of Continuing Education in Dentistry, no. 17, pp. S627-S630, 1994.

[43] I. Campos, A. L. F. Briso, L. A. F. Pimenta, and G. Ambrosano, "Effects of bleaching with carbamide peroxide gels on microhardness of restoration materials," Journal of Esthetic and Restorative Dentistry, vol. 15, no. 3, pp. 175-182, 2003.

[44] A. U. J. Yap and P. Wattanapayungkul, "Effects of in-office tooth whiteners on hardness of tooth-colored restoratives," Operative Dentistry, vol. 27, no. 2, pp. 137-141, 2002.

[45] E. J. Swift Jr. and J. Perdigão, "Effects of bleaching on teeth and restorations," Compendium of Continuing Education in Dentistry, vol. 19, no. 8, pp. 815-820, 1998.

[46] P. Wattanapayungkul and A. U. J. Yap, "Effects of inoffice bleaching products on surface finish of tooth-colored restorations," Operative Dentistry, vol. 28, no. 1, pp. 15-19, 2003.
[47] M. S. McCracken and V. B. Haywood, "Demineralization effects of 10 percent carbamide peroxide," Journal of Dentistry, vol. 24, no. 6, pp. 395-398, 1996.

[48] J. Da Costa, "Commentary. Effect of curing lights and bleaching agents on physical properties of a hybrid composite resin," Journal of Esthetic and Restorative Dentistry, vol. 20, no. 4, pp. 274-275, 2008.

[49] L. Greenwall, G. A. Freedman, V. V. Gordan, et al., Bleaching Techniques in Restorative Dentistry: An Illustrated Guide, Martin Dunitz, London, UK, 2001.

[50] R. W. Gerlach, R. D. Gibb, and P. A. Sagel, "A randomized clinical trial comparing a novel $5.3 \%$ hydrogen peroxide whitening strip to $10 \%, 15 \%$, and $20 \%$ carbamide peroxide tray-based bleaching systems," Compendium of Continuing Education in Dentistry, no. 29, pp. S22-S28, 2000.

[51] Council on Dental Materials and Devices, "Revised American dental association specification no.12 for denture base polymers," The Journal of the American Dental Association, vol. 90, no. 2, pp. 451-458, 1975.

[52] W. Buchalla, T. Attin, R.-D. Hilgers, and E. Hellwig, "The effect of water storage and light exposure on the color and translucency of a hybrid and a microfilled composite," Journal of Prosthetic Dentistry, vol. 87, no. 3, pp. 264-270, 2002.

[53] S. Inokoshi, M. F. Burrow, M. Kataumi, T. Yamada, and T. Takatsu, "Opacity and color changes of tooth-colored restorative materials," Operative Dentistry, vol. 21, no. 2, pp. 73-80, 1996.

[54] I. E. Ruyter, K. Nilner, and B. Möller, "Color stability of dental composite resin materials for crown and bridge veneers," Dental Materials, vol. 3, no. 5, pp. 246-251, 1987.

[55] W. M. Johnston and E. C. Kao, "Assessment of appearance match by visual observation and clinical colorimetry," Journal of Dental Research, vol. 68, no. 5, pp. 819-822, 1989. 


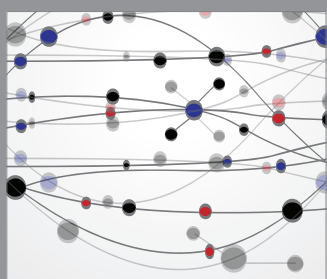

The Scientific World Journal
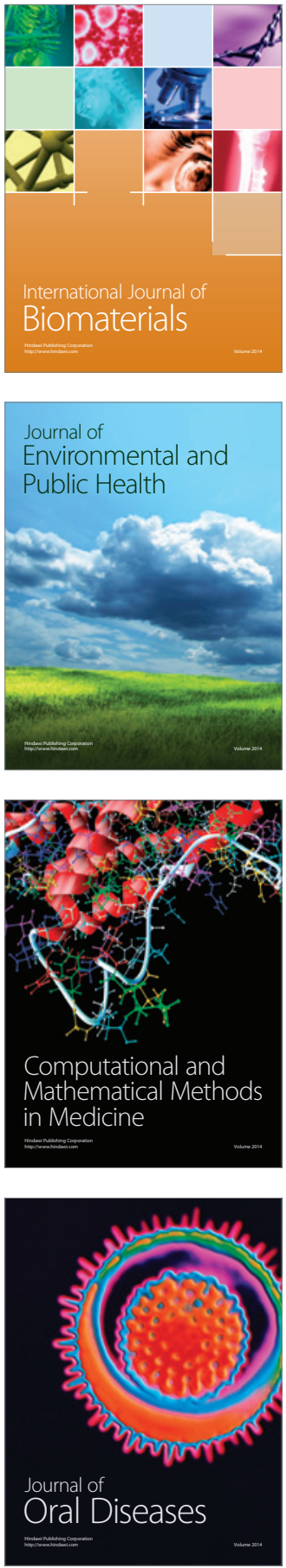
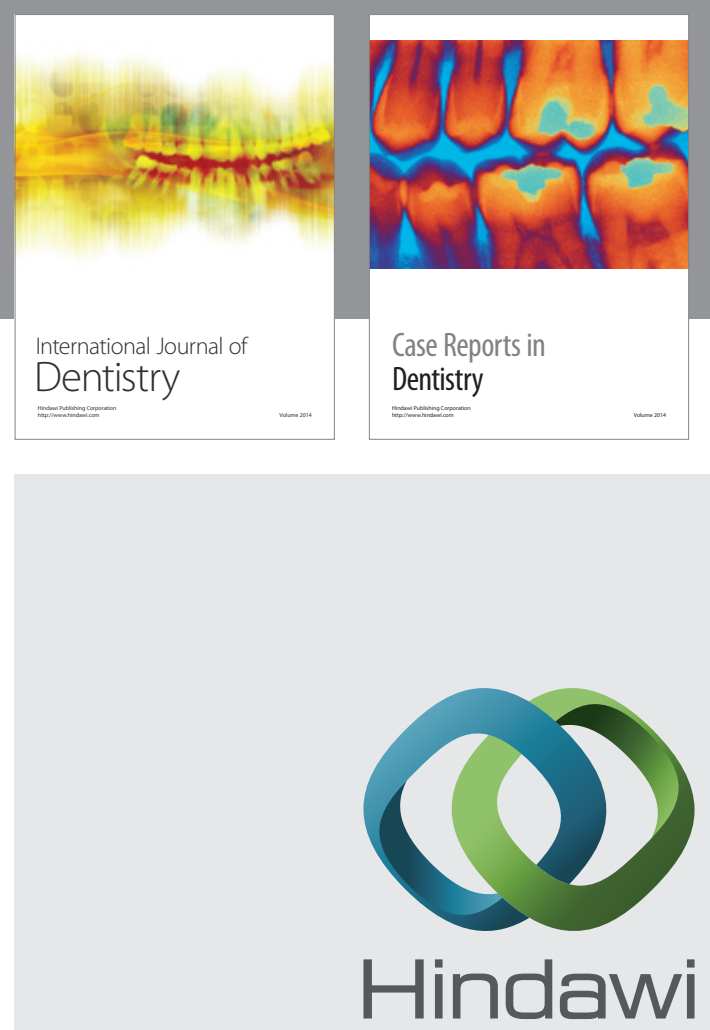

Submit your manuscripts at

http://www.hindawi.com
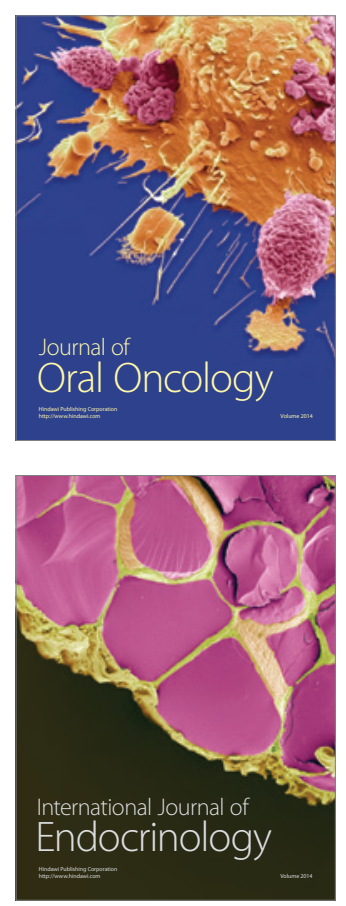
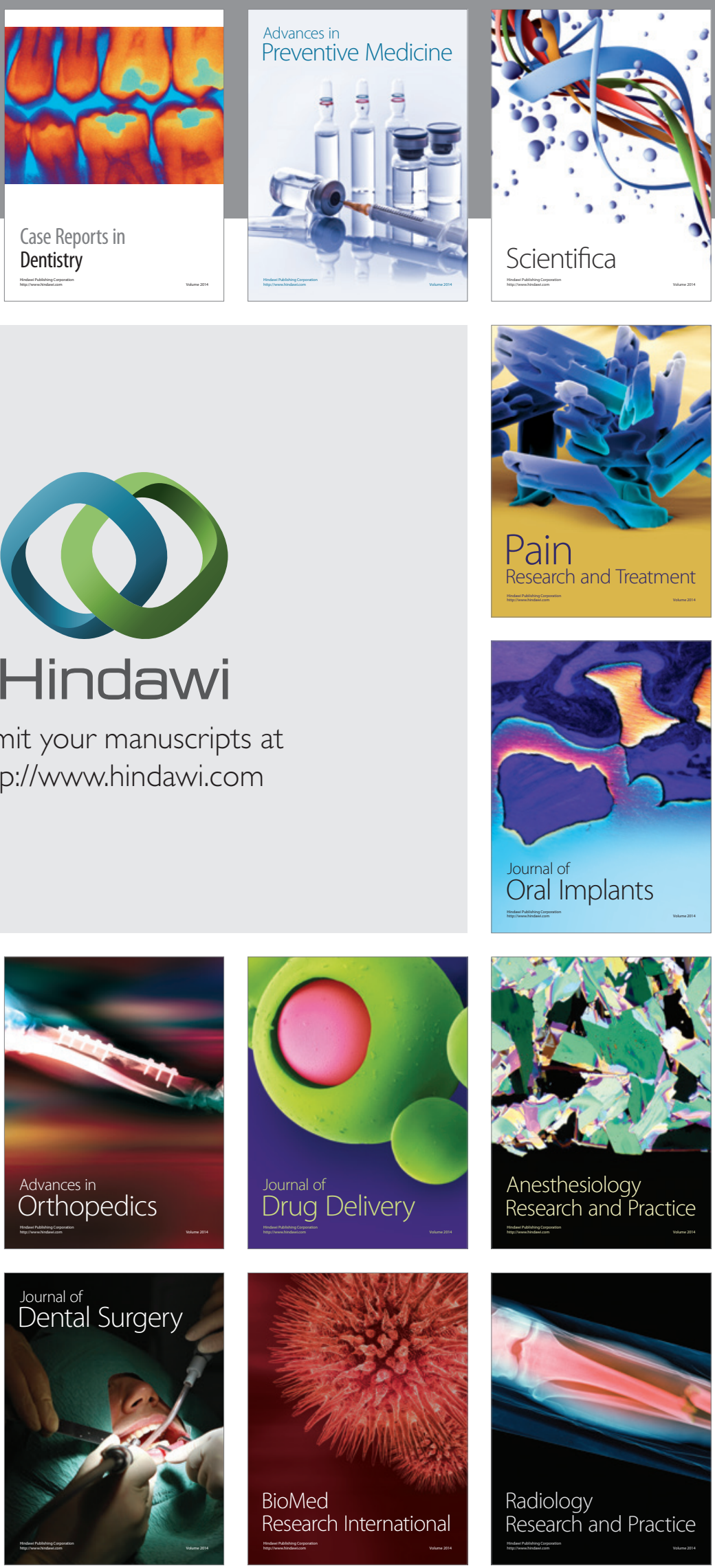